\title{
The influence of silver on the structure and mechanical properties of (TiAl)-based intermetallics
}

\author{
M.T. Vieira ${ }^{a}, *$ B. Trindade ${ }^{a}$, A.S. Ramos ${ }^{a}$, J.V. Fernandes ${ }^{b}$, M.F. Vieira ${ }^{c}$ \\ "ICEMS, Departamento Engonharia Mecânica, Universidade de Coimbra, Pinhal de Marrocos, 3030 Coinbra, Pontigal

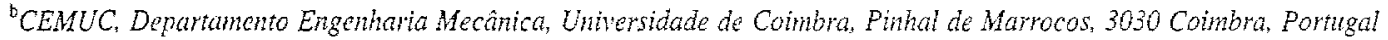 \\ "GMM/IMAT, Dipartanento Metulurgia e Materiais, Facudade de Engenharia do Porto, Rua dos Bragas, 4099 Porto, Portugal
}

\begin{abstract}
The infuence of silver on the structure and mechanical properties of sputter-deposited Ti-Al-Ag films with an aluminium content close to 48 at. $\%$ and $0<$ at. $\% \mathrm{Ag}<3$ was investigated. A new tensile test procedure has been developed to evaluate the ductility of the films. The results show that the as-deposited films are metastable formed, essentially, by an extended $\alpha$-Ti solid solution. Annealing at $600^{\circ} \mathrm{C}$ gives rise to the formation of $\gamma$-TiAl intermetallic compound. Silver does not lead to structural modifications of the TiAl system nor influences significantly its ductility. However, a hardness increase of the as-deposited fims with silver contents up to 1.6 at.\% is observed. C 1999 Elsevier Science S.A. All rights reserved.
\end{abstract}

Keywords: Sputtering; Titanium aluminides; Silver; Phase transitions; Mechanical properties

\section{Introduction}

Among the titanium aluminides, TiAl compounds are very attractive materiais for space flight vehicles, turbine engines and high-performance automotive engine components, owing to their low density, high temperature strength, high specific strength, modulus retention and excellent creep resistance [1]. However, the main disadvantage of these materials is their low ductility and fracture toughness at ambient and intermediate temperatures, which is the major impediment to a greater practical utilisation of the titanium aluminides $[2,3]$. In order to overcome this problem, refinement of grain size (to reduce slip length), addition of ternary alloying elements (to modify the structure) and heat treatment cycles (to alter the structure and morphology) have been used with more or less successful results $[1,4]$. In spite of the progress already reached in this field, an ideal commitment between mechanical properties and corrosion resistance has not been reached yet.

This work is part of a study concerning the effect of alloying elements on the structure, mechanical properties and corrosion resistance of sputter-deposited TiAl intermetallics thin films. In this paper, we evaluate the influence of silver on the mechanical properties of Ti-Al-Ag films in the as-deposited state and after heat treatment. The structure

* Corresponding author.

E-mail address: teresa.vieira@mail.dem.uc.pt (M.T. Vieira) and mechanical properties of temary $\mathrm{Ti}-\mathrm{Al}-\mathrm{Ag}$ as-deposited coatings will be discussed and compared to those after heat treatment.

\section{Expcrimental details}

Ti-Al-Ag thin films were co-deposited by d.c. magnetron sputtering onto 304 austenitic stainless steel (AISI) substrates, as described elsewhere [5]. The samples were studied on the as-deposited state and after heat treatment at $600^{\circ} \mathrm{C}$ during th in a hydrogenated argon atmosphere. This temperature was chosen on the basis of previous work concerning the decomposition of the as-deposited structure ( $\alpha$-Ti solid solution) into the intermetallic phase $(\gamma$-TiAl $)$ by means of differential scanning calorimetry.

The chemical composition of the films was determined by electron probe microanalysis using a Cameca SX50 apparatus. X-ray diffraction experiments were performed in a Philips X'Pert diffractometer with Co $\mathrm{K}_{\text {. radiation. Scan- }}$ ning electron microscopy was conducted in a $\$ 4100 \mathrm{Hitachi}$ equipment operating at $25 \mathrm{kV}$. The mechanical properties evaluated were the hardness and the ductility by means of hardness and tensile tests, respectively.

\subsection{Hardness tests}

The hardness tests were carried out on a computer controlled Fisherscope H100 ultramicrohardness tester, 


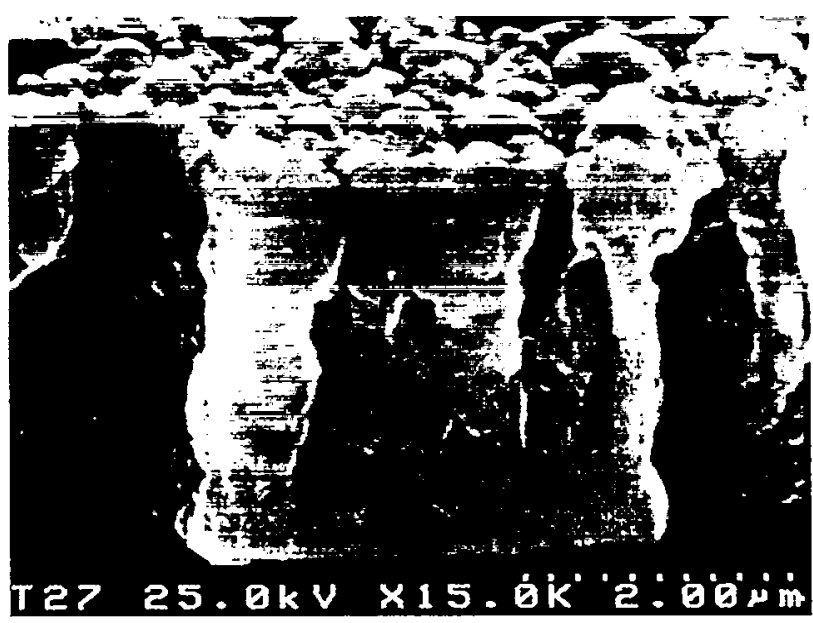

Fig. 1. Scanning electron microscopy cross-section image of the as-deposited TiAlAgin film.

equipped with a Vickers diamond indenter. In this work. nine tests at 300 and $70 \mathrm{mN}$ maximum load were performed in each sample. The hardness tests consisted in a loading stage followed by a 30 s holding period (creep) at the maximum load and an unloading stage down to $0.4 \mathrm{mN}$. This load was then maintained for another creep period of $30 \mathrm{~s}$. During the loading (unloading) stage. the load was increased (decreased) in 60 steps until the maximum (minimum) load was reached. For each step. the load and the penetration depth. $h$. were monitored as well as the time. $t$. during the creep periods.

The thermal drift in the penetration depth caused by
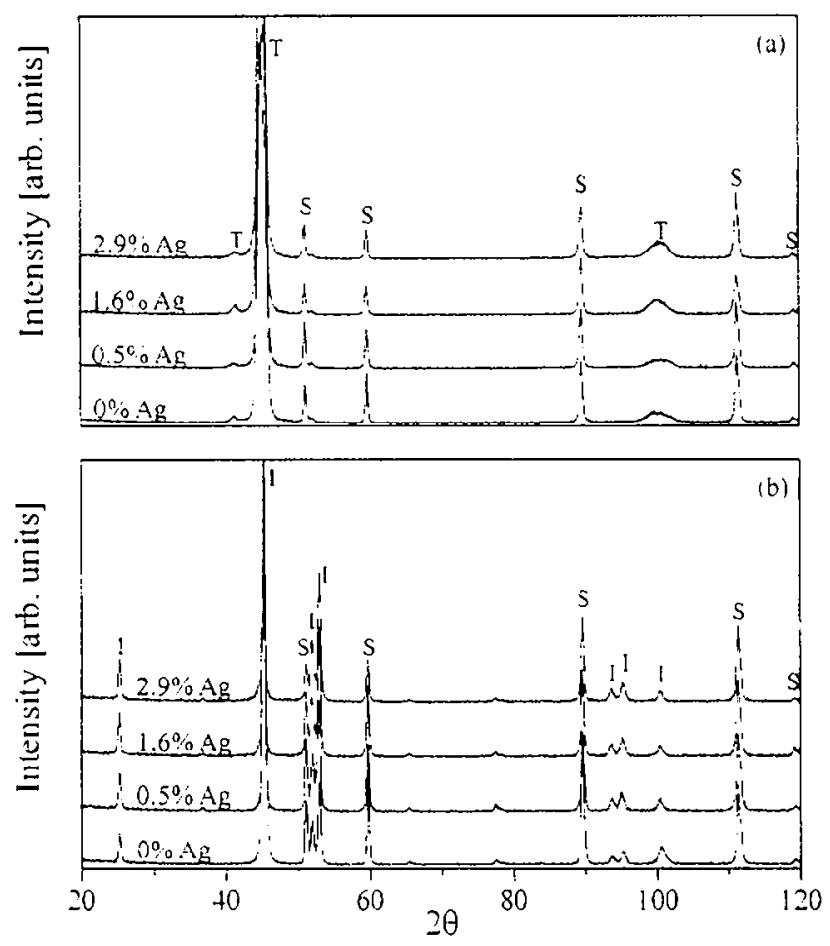

Fig. 2. X-ray diffractograns of the Ti-Al-Ag films (a) as-deposited and (b) heat treated. T: $\alpha-T i, I: \gamma-T i A l$, S: substrate. temperature fluctuations was corrected. This was obtained by linear fitting of the $h-t$ results during the last creep period: $h_{i d}=h \times t d \times \mathrm{l}$, where $t d$ is the thermal drift, i.e. the slope of the straight line resulting from the fitting.

After comection of the thermal drift, the load/penetration depth data were introduced in a computer programme in order to obtain the plastic penetration depth with the necessary geometric corrections allowing determining the hardness [6]. Nevertheless. this hardness concerns the composite substrate/film since substrate integration occurred during the tests. The substrate influence was climinated according to a method proposed by Fernandes [7] that allows obtaining the film's hardness. In this method, data of two different loads are requested which justifies the two maximum loads adopted.

\subsection{Tensile tests}

A new tensile test procedure has been developed to evaluate the ductility of the Ti-Al-Ag films produced. The tensile sample has a special geometry, with a continuously variable cross-sectional area. This allows obtaining a continuous strain gradient along the length of the sample during deformation. The minimum (A) and maximum (B) cross-sectional areas of the sample were such that in $B$ the deformation begins ( $\varepsilon \approx 0.01$ ) at the same time that in $A$ the strain is close to the limit of homogeneous plastic strain $(\varepsilon \approx$ 0.38 ). The calculations were perforned using the method described elsewhere for a two-region tensile sample [8].

To ensure a good accuracy in the evaluation of the relatively low ductility of the $\mathrm{Ti}-\mathrm{Al}-\mathrm{Ag}$ films, the tensile tests were pertomed up to a deformation in $A$ close to $\varepsilon=0.10$, being $B$ in the elastic domain. The Ti-Al-Ag film presents cracks in the region of the sample where the strain imposed to substrate exceeds the ductility of the film. Before rupture occurs in the film it was considered that the film and the substrate present similar plastic strains.

The deformation gradient in the sample was determined measuring the mean deformation of fifteen regions along the sample (each one with $5 \mathrm{~mm}$ long). The deformation was measured using a travelling microscope, having an accuracy of $1 \mu \mathrm{m}$.

\section{Results and discussion}

Fig. 1 shows a typical example of the surface and crosssection of the Ti-Al-Ag films. The surface of the film presents a uniform "granular" aspect that should be a consequence of the co-sputtering process, which promotes an island-like growing. The film's cross-section, although rather dense. exhibits morphology with a slightly columnar feature.

$\mathrm{X}$-ray diffraction patterns obtained for the Ti-Al-Ag films before and after annealing at $600^{\circ} \mathrm{C}$ are shown in Fig. 2a,b, respectively. Regarding the as-deposited films, the structure of the Ti-Al film was identified as a supersaturated titanium 


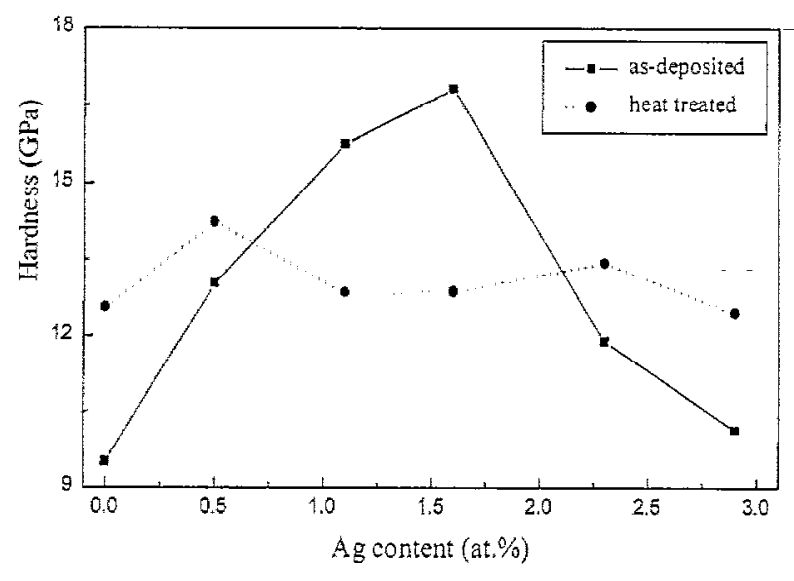

Fig. 3. Hardness of as-deposited and heat treated Ti-A-Ag films as function of the Ag content.

solid solution ( $\alpha$-Ti) with a slight shift towards the higher angles and a (00.2) texture. According to the Ti-Al phase diagram this film $\left(\mathrm{Ti}_{52}-\mathrm{Al}_{48}\right)$ should lie in a $\gamma$-TiAl domain instead of a $\alpha$-Ti one. In equilibrium, $\alpha-T i$ exists at room temperature up to a maximum aluminium content of $\approx 12$ at. \%. In our case, $\alpha$-Ti exists at room temperature with $\approx 50$ at.\% of Al. The basic reason for a metastable solid solution forming under such conditions might he envisaged on the sputtering process [9]. The high cooling rates reached by this process give rise to a low mobility of the adatoms.

The introduction of silver in the Ti-Al system does not seem to have an important role on the structure of the asdeposited films. In fact, inspection of X-ray diffractograms, recorded from films with and without silver. do not reveal any structural differences. Based on this result, two hypothesis may be advanced: (i) silver is in solid solution in the $\alpha-$ Ti structure or (ii) silver induces the formation of a second phase, too fine to be detected by X-ray diffraction. Another possibility is to consider both hypothesis correct, i.e., the solubility of silver in the $\alpha$-Ti phase is limited and precipitation of a fine-grained phase occurs above a certain silver content in the films.

Concerning the heat-treated samples (Fig. 2b), the X-ray diffractograms show that is possible to obtain an intermetallic compound ( $\gamma$-TiAl [10]) by the decomposition of the sputtered metastable supersaturated $\alpha$-Ti phase at $600^{\circ} \mathrm{C}$. Again, as in the as-deposited structure, the role of silver in

Table 1

Ductility of the as-deposited and heat treated Ti-Al-Ag films

\begin{tabular}{llll}
\hline Silver (at.\%) & Ductility (\%) & \\
\cline { 2 - 4 } & As-dieposited & Hear treated \\
\hline 0 & 2.4 & 1.4 & \\
0.5 & - & 1.3 & - \\
1.1 & 1.7 & 1.6 & - \\
1.6 & 1.8 & 1.2 & \\
2.3 & - & 0.8 & \\
2.9 & 2.0 & 1.0 \\
\hline
\end{tabular}

the $\gamma$-TIAl is not conclusive. In fact, silver does not seem to influence the $\alpha$-Ti $\rightarrow \gamma$-TiAl transformation and the X-ray diffraction technique does not reveal the appearance of new crystalline phases. However, the X-ray diffraction peaks of the $\gamma$-TiAl containing silver are shifted to higher diffraction angles. This might indicate that silver is partially dissolved in the intermetallic compound. The remaining silver atoms should form a new phase (nanocrystalline or amorphous) not detectable by $\mathrm{X}$-ray diffraction.

\subsection{Hardness results}

The hardness results obtained for the as-deposited and heat treated films are plotted in Fig. 3 as function of the silver content. The more relevant feature is that for the asdeposited samples the hardness increases with the silver content until a maximum value of $17 \mathrm{GPa}$ and then it decreases down to $10 \mathrm{GPa}$, while the hardness of the heat treated films is not infuenced by the presence of silver. It should be noted that the hardness of the sputter-deposited TiAl thin film is higher than that of bulk TiAl, as usually observed by sputtering other elements/compounds [11].

The shape of the hardness curve of the as-deposited films might strengthen the mentioned hypothesis of the silver solubility in the $\alpha$-Ti phase. For low silver contents, it is likely that this element is in solution, contributing for the hardening of the stucture. For higher silver contents, $\alpha-T i$ hypothetically is supersaturated in silver giving rise to a soft fine-grained phase, not possible to detect by $\mathrm{X}$-ray diffraction.

In the case of the annealed films, the formation of $\gamma$-TiAl intermetallic occurs with hardening of the structure. Indeed, one of the mechanical characteristics of the intermetallic ordered structures is their high hardness relative to the conventional disordered solid solutions [12]. The presence of silver does not lead to a hardness increase of the $\gamma$-TiAl. Thus, one might conceive a silver rejection from this structure during annealing.

\subsection{Tensile tests results}

Table 1 compiles the results of ductility obtained by tensile testing from the as-deposited and heat treated Ti$\mathrm{Al}-\mathrm{Ag}$ films. The ductility of the annealed films is lower than the corresponding one in the as-deposited state. The highest value corresponds to the $\alpha$-Ti as-deposited structure without silver. Whilst the incorporation of this element is prejudicial in the case of the as-deposited samples, for the heat treated films this effect is only notorious for the higher silver contents. Besides possessing a low ductility, the untreated samples with silver detach from the steel substrate during the tensile tests. Typically, the presence of silver in a free state leads to loss of the adhesion to the substrate. The treated TiAl film has a ductility close to that of the bulk material $(1-3 \%$ [13]) which is a good result taking into account the hardening effect due to the sputtering process. Finally, the results agree with the expected hardness/ducti- 
lity interdependence: the higher the hardness the lower the ductility.

\section{Conclusions}

The results show that it is possible to obtain TiAl-based intermetallics by sputtering after $600^{\circ} \mathrm{C}$ annealing of the asdeposited $\alpha$-Ti metastable solid solution. Silver does not lead to structural modifications of the TiAl system nor gives rise to significant improvements of its mechanical properties. However. it should be noted a hardness increase of the as-deposited films with silver contents up to 1.6 at. \%.

\section{Acknowledgements}

This work was supported by Fundação para a Ciência e Tecnologia. Portugal, through a PRAXIS XXI program (contract CTA/1904/95 and BD/3623).

\section{References}

[1] C. Suryanarayana, F.H. Froes, Mater. Sci. Eng. A 179/180 (1994) 108.

[2] Y.G. Li, M.H. Loretlo. Acla Metall, Mater. 12 (1994) 2009.

[3] T. Shimizu. T. Iikubo. S. Isobe. Mater. Sci. Eng. A 153 (1991) 60?

[4] M. Onhuma. T. Abe. H. Onodera, in: Prox. Conf. MRS Symp., Vol. 40. Materials Research Society, LSA, 1996. p. 209

[5] M.T. Vieira. B. Trindade. A.S. Ramos, C. Coelho, Intermetallics thin films: from projuction to characterisation in a salt ensironment. accepted for oral presentation in Euromat'98. Lisbon. 1998.

[6] A.C. Trindade, A. Cavaleiro. J.V. Fernandes. J. Test. Eval. 22 (1994) 365.

[7] J.V. Fernandes, A.C. Trindade. L.F. Menezes. The coated surface hardness: an empirica! model. J. Mater. Res.. (1998) submitted.

[8] J.V. Fernandes, M.F. Vieira, Metall Aater. Trans. A 28 (1997) 1169.

[9] B. Trindade, M.T. Vieira, E. Bauer-Grosse, Acta Mater. 46 (1998) 1731.

[10] International Center for Diffraction Dalta, card 5-678. Pennsylvania.

[11] D.S. Rickerby, P.J. Burnet,, Thin Solid Filins 157 (1988) 195.

[12] G. Sauthoff, in: R.L. Fleisher. J.II. Westbrook (Eds.). Intermetallic Compounds: Principles and Practice. I. W'iley, Chichester. 1995.

[13] S.C. Huang, J.C. Chesnutt, in: J.H. Westbrook, R.L. Fleisher (Eds.), Incermetallic Compounds: Principles and Práctice, 2. 1995 